(c) American Dairy Science Association, 2006.

\title{
Genetics of Body Condition Score in New Zealand Dairy Cows
}

\author{
J. E. Pryce ${ }^{1}$ and B. L. Harris \\ Livestock Improvement Corporation Ltd., Private Bag 3016, Hamilton, New Zealand
}

\begin{abstract}
Body condition score (BCS) data were collected on 169,661 first-parity cows from herds participating in progeny testing schemes and linear type assessment. Genetic and residual variances for BCS estimated across time using a quadratic random regression model were found to be largest at the start of lactation. Heritability estimates ranged from 0.32 to 0.23 from $\mathrm{d} 1$ to 200 of lactation, with a mean of 0.26 . Genetic correlations between BCS and other traits were estimated using 2 approaches: 1) a multivariate analysis that included BCS and live weight, both adjusted for stage of lactation; 270-d cumulative yields of milk, fat, and protein; average somatic cell score; and 2 measures of fertility; and 2) a bivariate random regression analysis in which BCS was considered to be a longitudinal trait across time, with the same measurements as in approach 1 for all other traits. Genetic correlations of BCS with the 2 fertility traits were 0.43 and 0.50 using the multivariate analysis; the corresponding random regression estimates between BCS as a longitudinal trait across time and 2 measures of fertility were 0.35 to 0.44 and 0.40 to 0.49 , and tended to increase with stage of lactation. Genetic correlations estimated using the random regression model fluctuated around the multivariate estimates for live weight and somatic cell score, which were 0.50 and -0.12 , respectively. Genetic correlations estimated using the multivariate analysis of BCS with fat and protein yields were close to zero. With the random regression model, genetic correlations between BCS and fat and protein yields were positive at $d 1$ of lactation ( 0.16 and 0.08 , respectively) and were negative by d 200 of lactation ( -0.25 and -0.20 , respectively). In pastoral production systems, such as those typical in New Zealand, there appears to be an advantage in the total lactation yields of fat and protein for cows of higher BCS in early lactation, which is likely to be because these cows have body reserves that are available to be mobilized in later lactation, when feed resources are sometimes limited.
\end{abstract}

Received March 21, 2006.

Accepted June 7, 2006.

${ }^{1}$ Corresponding author: jpryce@lic.co.nz
Key words: random regression model, body condition score, fertility

\section{INTRODUCTION}

Body condition score is an approximate way of judging the body lipid content of a cow (Garnsworthy, 1988). Although subjective, it is currently a favored practical method of evaluating body energy stores. It is assessed by either visual appraisal (Edmondson et al., 1989), or by feeling the spinous processes of the loin and around the tail area (Garnsworthy, 1988).

Several authors have estimated covariance functions for BCS using random regression (RR) models (e.g., Koenen and Veerkamp, 1998; Jones et al., 1999; Veerkamp and Thompson, 1999; Veerkamp et al., 2001; Berry et al., 2003; Dechow et al., 2004). Veerkamp et al. (2001) and Berry et al. (2003) extended the RR methodology to estimate genetic correlations between data that repeat across time, such as BCS, live weight (LWT), and milk yield, with measurements available at a single point in lactation, such as fertility. Veerkamp et al. (2001) suggested that traits related to energy balance, such as milk yield, BCS, and LWT, should be investigated as a function of lactation stage, because the duration and size of energy deficit vary across lactation, which could affect genetic correlation estimates.

In New Zealand, feed requirements for production are generally matched to pasture supply, and consequently an important management strategy is to have a single concentrated seasonal calving pattern so that feed usage is optimized. A period of slow grass growth and reduced pasture availability is sometimes experienced if there are dry conditions in the summer months (typically January to March), which corresponds to late lactation. During this time, mobilization of body tissue reserves is common to sustain lactation. Genetic correlations between BCS and milk production traits estimated using multivariate models have been reported to be close to zero using New Zealand data (Pryce and Harris, 2004; Harris et al., 2005). This contradicts research from the United States and Ireland (Dechow et al., 2001; Berry et al., 2003), where genetic correlations between BCS and milk production traits have been reported to be negative. This genetic correlation appears to be system dependent. Investigating the genetic rela- 
tionship between BCS and milk production across time using data from cows fed pasture may help our understanding of this complex relationship.

If genetic correlations between BCS and other traits of importance in the New Zealand breeding goal vary across lactation, this may have further implications. For example, it may be useful to provide genetic evaluations of BCS at particular stages of lactation, especially for fertility, where BCS is already used as a genetic predictor (Harris et al., 2005).

The main aim of the present study was to estimate genetic variation of BCS as a function of time and to investigate the genetic relationship between BCS and other traits under selection in New Zealand. The national breeding index is Breeding Worth and currently includes 270-d yields of milk, fat, and protein; LWT; fertility; residual survival; and SCS. Residual survival is survival after all other traits in Breeding Worth are excluded, so genetic correlations between this trait and other traits in the index are zero. The analyses undertaken were 1) to estimate genetic (co)variances of BCS longitudinally across first-lactation data using RR models; and 2) to estimate genetic correlations of BCS with other traits under selection in New Zealand using a) multivariate and b) RR models, where BCS was considered to be a repeated trait across lactation and other traits were single measurements.

\section{MATERIALS AND METHODS}

\section{Data}

The BCS data were collected on 169,661 first-parity cows in herds that participated in the progeny testing (PT) schemes of either Livestock Improvement or Ambreed (Hamilton, New Zealand), or that participated in linear type classification, known in New Zealand as the Traits Other than Production (TOP) inspection, from the 2000-2001 through the 2003-2004 seasons. Approximately half of the cows were from PT herds; the rest of the cows were from pedigree herds. Both Holstein-Friesian and Jersey breeds and their crosses were represented in the data.

At least 2 BCS measurements were taken in the PT herds. The first coincided with recording of LWT and the second was at the time of TOP inspection. In the herds not participating in PT, one BCS measurement was taken at the time of TOP inspection. Inspectors received training to evaluate BCS. Scoring was done visually on a 1 to 9 scale. A single LWT record per cow was available for animals that participated in PT and was recorded on the same day as the PT BCS measurement.

Additional data on fertility; milk, fat, and protein yields; SCS; breed; and pedigree were extracted from the New Zealand Dairy core database and the Livestock Improvement national database. Breed proportions of the animal and its sire and dam were available in 16ths, which allowed the estimation of both breed and heterosis effects (Koch et al., 1985). Proportions of Jersey (J), Holstein-Friesian of New Zealand ancestry (NZHF), and Holstein-Friesian of North American and European ancestry (NAHF) were calculated. A more detailed description is provided by Harris and Kolver (2001).

Yield deviations, for cumulative first-lactation milk (MY270), fat (FY270), and protein (PY270) expressed to a standardized lactation length of $270 \mathrm{~d}$ were calculated using the method of Johnson (1996). This method adjusts for the test-day environment, takes account of culling, and weights test-day records according to the number of tests, stage of lactation, and interval between tests. Yield deviations were expressed with respect to herd-year-season-age contemporary groups.

Test-day records on SCS were available on 61,134 animals of the animals that had BCS records (these were Livestock Improvement's PT animals). Following Harris and Winkelman (2004), a logarithmic transformation to the base 2 was used to transform SCC and the lactation mean per animal was calculated; this value was deviated from the mean logarithmic-transformed SCC of contemporaries within the same herdyear.

The fertility measures used in the analyses were presented for mating within the first $21 \mathrm{~d}$ of the mating season (PM21), scored as a binomial trait to allow for cows in different stages of their reproductive cycle. The second fertility measure was calving within $42 \mathrm{~d}$ from the planned start of calving (CR42), also scored as a binomial trait. If the culling reason was recorded as infertility, then the CR42 record was set to be zero. Cows culled for other reasons were treated as missing data. Full details of the methodology used to calculate the fertility measures is given in Harris et al. (2005).

\section{RR Analysis}

Legendre polynomials were used to model the additive genetic covariance function. Starting values of additive genetic variances of Legendre polynomials for the longitudinal analysis of BCS were obtained from (co)variances estimated from a 4-trait multivariate analysis of BCS derived by dividing data into approximately equal-sized blocks according to the interval from calving to observation date following the procedure described by Kirkpatrick et al. (1990). The cut-off points for the blocks were 21 to $62 \mathrm{~d} ; 62$ to $90 \mathrm{~d}$; 90 to $111 \mathrm{~d}$; and 111 to $200 \mathrm{~d}$. The software used to do the analysis was the average information REML algorithm (AI-REML) of Johnson and Thompson (1995) that 
allows for missing data. A sire model was fitted that included a pedigree of 14,631 males and traced back to male ancestors born in 1939 in some cases. Ancestors without parentage details were assigned to phantom parents that were in turn assigned to a genetic group according to birth year, with the provision of allowing crossbred animals to have more than one genetic group. The fixed effects in the model included 1) herd-year; 2) type of BCS measurement (PT or TOP); 3) breed proportions of NZHF, NAHF, and J, and heterozygosity effects of each combination of breeds; and 4) age at calving and DIM as linear and quadratic covariates.

Previous research using a similar data set (Pryce and Harris, 2004 and Pryce et al., 2005) and results published from other studies (Veerkamp et al., 2001; Berry et al., 2003) indicate little advantage in going beyond a quadratic RR model to estimate genetic (sire) variance of BCS. Therefore, an additive genetic sire model including the quadratic $\mathrm{RR}$ model was used to estimate the genetic covariance function of BCS.

Based on the results of Pryce et al. (2005), a model that allowed the residual error variance to change with stage of lactation was preferable to a model in which the residual variance was assumed to be constant. This type of model was obtained by fitting a link function accounting for heterogeneity of error variance (Jaffrezic et al., 2000) in a 2-stage process. To achieve this, the residual value for each observation was derived from the $R R$ model. These residuals were squared and fitted to a second-order Legendre polynomial of DIM using a log link and assuming a gamma distribution. The predicted error variance for each observation was used to form weights in the subsequent RR analysis. This process was repeated 4 times.

A permanent environmental effect was fitted as a random nonadditive effect because some cows had 2 BCS records. Herd-test-day was fitted as a fixed effect in addition to 1) type of BCS record (PT or TOP); 2) age at calving as a linear and quadratic covariate; and 3) breed proportions of NAHF, NZHF, and $J$ and heterosis of combinations of these breeds. Heterogeneity of sire and residual error variances, constant environmental effect variances, and the fixed effects were estimated using a sire model in ASREML (Gilmour et al., 2002).

\section{Genetic Relationship Between BCS and Other Traits}

To estimate the genetic relationship between BCS and other traits, a multivariate analysis was undertaken with a single BCS observation per cow. Where cows had 2 measurements (TOP and PT), the PT BCS measurement was used, because the DIM for BCS and LWT measurements were the same. The model fitted to BCS and LWT included 1) linear and quadratic terms for age (in days); 2) linear and quadratic terms for DIM; 3) breed proportions of NAHF, NZHF, and J and associated heterosis effects, and 4) herd-year contemporary group. For all other traits in the multivariate analysis (MY270, FY270, PY270, PM21, CR42, and SCS), the same model was fitted, except with the exclusion of DIM from the model. Heritabilities, genetic and phenotypic correlations, and fixed effects were estimated using REML with a multivariate linear sire model that included genetic groups using the average information algorithm of Johnson and Thompson (1995).

To investigate how genetic correlations between BCS as a longitudinal trait and other traits behaved, 2 models were used: 1) a multivariate analysis that included each trait independently (from MY270, FY270, PY270, LWT, PM21, CR42, and SCS), where the BCS data were split into 4 approximately equal-sized blocks of data according to the stage at which BCS was measured and each block of data was treated as a separate BCS trait (as described earlier); and 2) the RR model extended to a multivariate analysis, where the aim was to estimate genetic correlations between BCS considered to be a longitudinal trait and other traits (MY270, FY270, PY270, LWT, PM21, CR42, and SCS) included one at a time and as single time points. The covariance between the intercept and linear terms of BCS and the trait under analysis were consistently different from zero; however, the quadratic term was always close to zero. Therefore, the model was simplified to include linear Legendre polynomials fitted to BCS to estimate the covariance function of BCS with other traits. Because the purpose of this analysis was to estimate genetic correlations, the model fitted to BCS assumed homogeneous residual variation across lactation, because estimates of residual variation (for BCS) were not required for the calculations.

\section{RESULTS}

In the plot of mean phenotypic BCS on each day from calving (Figure 1), one can see that BCS at calving was approximately 4.6 , and dropped to approximately 3.9 from d 40 to 60 . The BCS measurement collected at TOP inspection was generally assessed before the PT observation, with medians of 87 and $102 \mathrm{~d}$, respectively. From both schemes, 99\% of BCS data was collected between d 9 and 196 of lactation. Thus, for the analyses presented in this paper, only BCS measurements up to d 200 were included in the analyses and are presented in the results.

The percentages of cows that could be described as predominantly (>13/16) Holstein-Friesians and Jerseys were 46 and $26 \%$, respectively, with the remaining $28 \%$ being crosses between these 2 breeds (predominantly). 


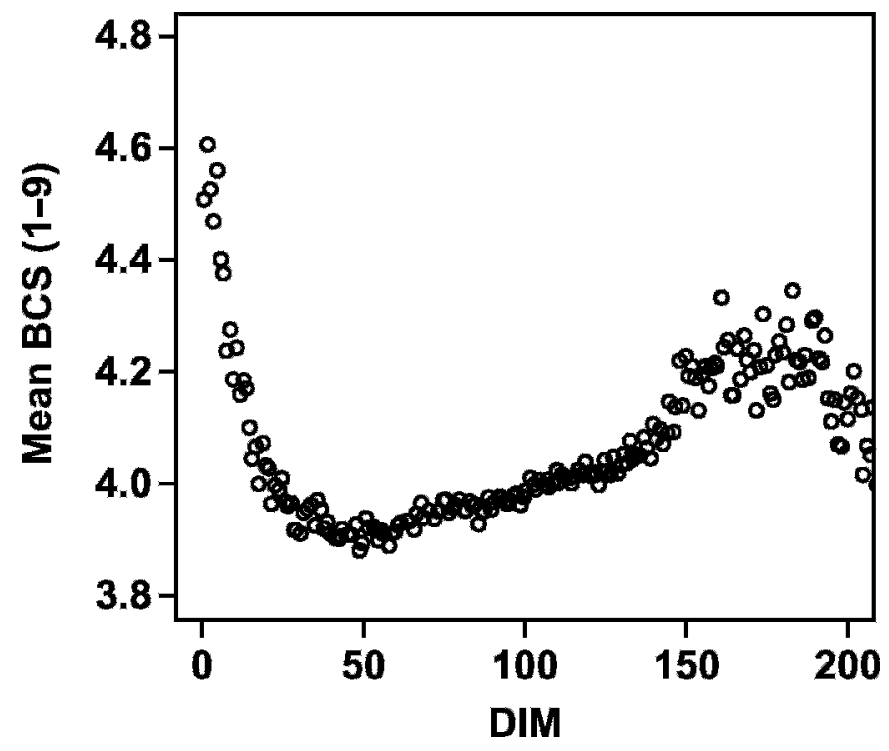

Figure 1. Mean phenotypic BCS plotted against the interval from calving to BCS measurement.

Breed and heterosis estimates of BCS are presented in Table 1; the BCS of $\mathrm{J}$ and NAHF were both approximately 0.3 lower than NZHF. Small yet significant estimates of heterosis were obtained, with first crosses having between 0.057 and 0.066 higher units of BCS than purebreds.

\section{Genetic Variances of BCS}

The residual variance decreased from $d 1$ to 200 of lactation (Figure 2), indicating that residual variation was heterogeneous across lactation. Genetic variation was highest in early lactation, with the peak heritability corresponding to the highest estimate of genetic variation at the start of lactation (Figure 3 ). The range in heritability estimates was from 0.32 (d 1) to 0.23 (d 200 ). In the period in which there was the most data (around $d 50$ to 150), heritability estimates were very consistent ( 0.25 to 0.27 ). The simple mean of the heritability was 0.26 . The mean heritability estimate was

Table 1. Breed and heterosis effects of BCS

\begin{tabular}{lc}
\hline Breed effect $^{1}$ & BCS \\
\hline $\mathrm{J}$ & -0.438 \\
$\mathrm{NZHF}$ & -0.124 \\
$\mathrm{NAHF}$ & -0.431 \\
$\mathrm{~J} \times \mathrm{NZHF}$ & 0.057 \\
$\mathrm{~J} \times \mathrm{NAHF}$ & 0.060 \\
$\mathrm{NZHF} \times \mathrm{NAHF}$ & 0.066 \\
\hline
\end{tabular}

${ }^{1} \mathrm{~J}=$ Jersey; NZHF = New Zealand Holstein-Friesian; NAHF = Holstein-Friesian whose ancestors trace back to North America.

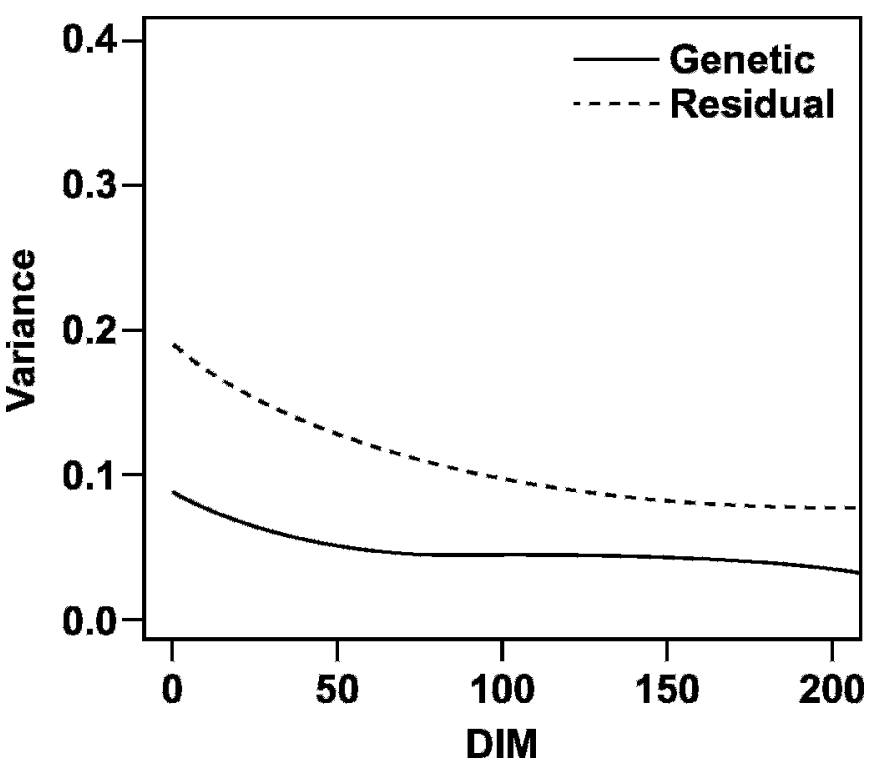

Figure 2. Genetic and residual error variances.

higher than obtained using PT and TOP data from the multivariate analysis of BCS data split into 4 parts according to DIM, which ranged from 0.20 (SE 0.02) to $0.22(0.02)$.

Genetic correlations between BCS measured at $\mathrm{d} 60$ of lactation and BCS at other stages of lactation are shown in Figure 4. Genetic correlations were lowest at the peripheries $(0.85$ at $\mathrm{d} 1$ from calving and 0.78 at $d$ 200 from calving).

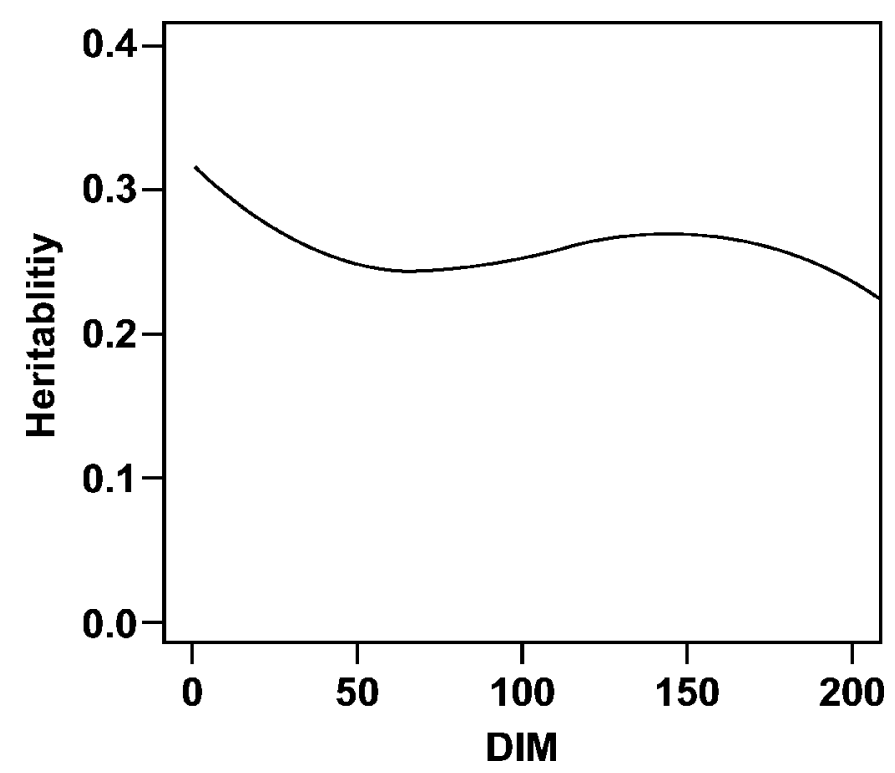

Figure 3. Heritability estimates of BCS across time. 


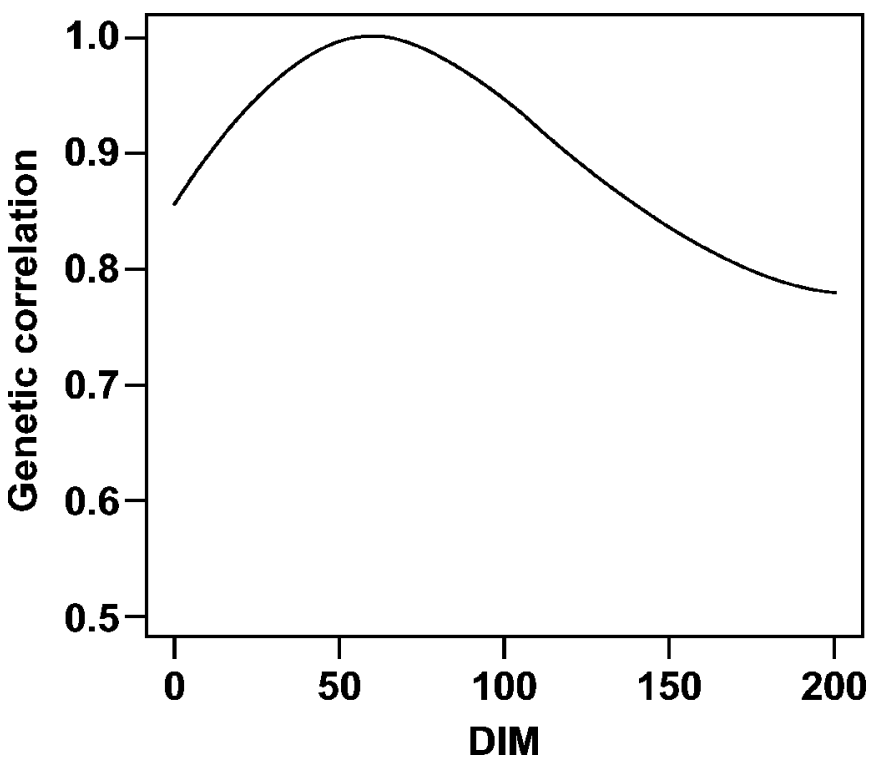

Figure 4. Genetic correlations of BCS recorded at d 60 with BCS recorded at other intervals from calving.

\section{Genetic Correlations Between BCS and Traits in Breeding Worth Index}

Heritabilities and genetic and phenotypic correlations among BCS, MY270, FY270, PY270, PM21, CR42, SCS, and LWT are presented in Table 2. The heritability of BCS was 0.21, which was consistent with the estimates obtained from the multivariate analysis of BCS divided into 4 parts according to stage of lactation. Heritabilities of fat and protein yields were 0.29 and milk volume was 0.36 . Fertility measures had heritability estimates of 0.068 and 0.029 for PM21 and CR42, respectively.

Genetic correlations between BCS and fat and protein yields estimated using the multivariate model were close to zero ( -0.03 and -0.06 , respectively). With the RR model (Figure 5), genetic correlations between BCS and fat and protein yields were positive at $\mathrm{d} 1$ of lactation ( 0.16 and 0.08 for fat and protein, respectively) and were negative by d 200 of lactation $(-0.25$ and -0.20 , respectively). The genetic correlation with milk yield was -0.13 when using the multivariate analysis (Table 2 ) and between 0 (at d 1) and -0.13 (d 200) in the RR analysis (Figure 5).

Genetic correlations between BCS and fertility traits estimated using a multivariate model were high $(0.50$ and 0.43 for PM21 and CR42, respectively, as shown in Table 2). With RR (Figure 6) they increased across lactation, peaking at around d 160 of lactation. Genetic correlations between BCS and PM21 increased from 0.35 to 0.44 , whereas those between BCS and CR42 increased from 0.40 to 0.49 .

The genetic correlation with SCS was small and negative $(-0.12)$, whereas BCS was strongly correlated with LWT. The genetic correlation estimates between BCS and both SCS and LWT estimated using the RR model were very consistent with estimates from the multivariate analysis. Phenotypic correlations of BCS with these traits were generally smaller than genetic correlations, but were in the same direction from zero. Other genetic and phenotypic correlations between traits are presented in Table 2.

Table 2. Correlations between traits currently included in the New Zealand Breeding Worth Index ${ }^{1}$

\begin{tabular}{lcccrrrrr}
\hline Trait & FY270 & PY270 & MY270 & PM21 & CR42 & SCS & LWT & BCS \\
\hline FY270 & $\mathbf{0 . 2 9 4}$ & 0.821 & 0.73 & 0.015 & 0.015 & -0.087 & 0.239 & -0.039 \\
& 0.011 & 0.001 & 0.002 & 0.003 & 0.003 & 0.005 & 0.004 & 0.004 \\
PY270 & 0.691 & $\mathbf{0 . 2 9 4}$ & 0.911 & 0.017 & 0.017 & -0.096 & 0.299 & -0.031 \\
& 0.015 & 0.012 & 0.001 & 0.003 & 0.003 & 0.005 & 0.004 & 0.004 \\
MY270 & 0.549 & 0.864 & $\mathbf{0 . 3 5 8}$ & -0.013 & -0.002 & -0.125 & 0.248 & -0.089 \\
& 0.019 & 0.007 & 0.013 & 0.003 & 0.003 & 0.005 & 0.004 & 0.004 \\
PM21 & -0.098 & -0.132 & -0.225 & $\mathbf{0 . 0 6 8}$ & 0.253 & -0.01 & 0.106 & 0.136 \\
& 0.04 & 0.04 & 0.039 & 0.005 & 0.003 & 0.004 & 0.004 & 0.004 \\
CR42 & -0.061 & -0.05 & -0.146 & 0.859 & $\mathbf{0 . 0 2 9}$ & -0.016 & 0.053 & 0.071 \\
& 0.052 & 0.053 & 0.052 & 0.034 & 0.003 & 0.004 & 0.004 & 0.004 \\
SCS & 0.115 & 0.062 & 0.043 & -0.148 & -0.107 & $\mathbf{0 . 1 7 5}$ & 0.039 & 0.014 \\
& 0.045 & 0.046 & 0.045 & 0.057 & 0.073 & 0.012 & 0.005 & 0.005 \\
LWT & 0.327 & 0.357 & 0.281 & 0.171 & 0.025 & -0.013 & $\mathbf{0 . 3 9 1}$ & 0.4 \\
& 0.03 & 0.029 & 0.03 & 0.042 & 0.056 & 0.043 & 0.017 & 0.003 \\
BCS & -0.032 & -0.062 & -0.13 & 0.497 & 0.433 & -0.117 & 0.502 & $\mathbf{0 . 2 1 2}$ \\
& 0.036 & 0.036 & 0.035 & 0.04 & 0.056 & 0.047 & 0.028 & 0.011 \\
\hline
\end{tabular}

${ }^{1}$ Genetic correlations shown below the diagonal, phenotypic above, and heritabilities in boldface along the diagonal. Standard errors are shown below the estimates. FY270 $=270$-d cumulative yield of milk fat; PY270 = 270-d cumulative yield of milk protein; MY270 = 270-d cumulative volume of milk; PM21 = presented for mating within $21 \mathrm{~d}$ from the planned start of mating; CR42 = calving rate within $42 \mathrm{~d}$ from the planned start of calving; LWT = live weight. 
A

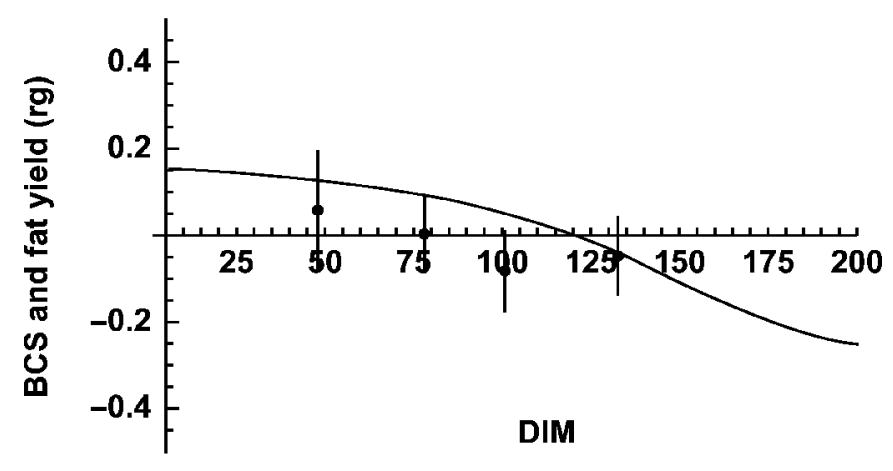

B

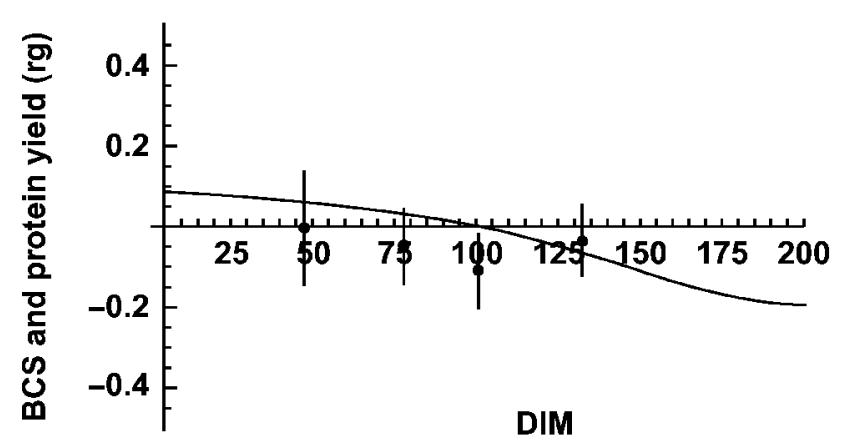

C

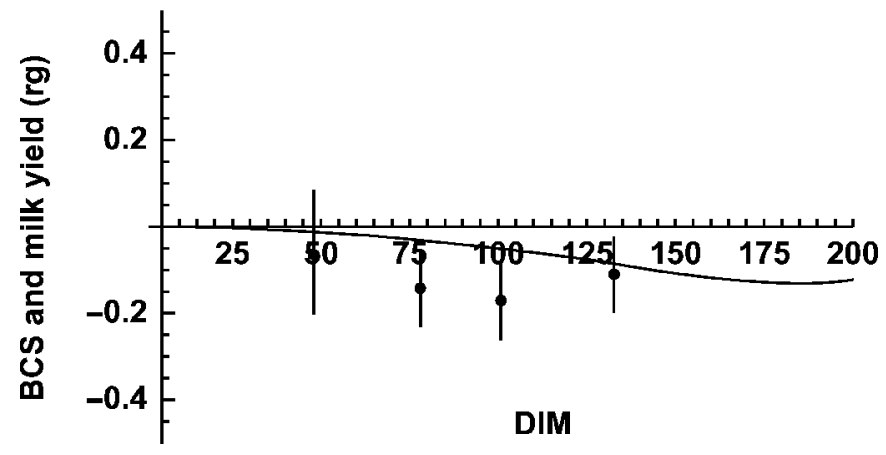

Figure 5. Genetic correlations (rg) between BCS and (A) 270-d yield of fat, (B) 270-d yield of protein, and (C) 270-d yield of milk (including 95\% confidence intervals, indicated by bars, of genetic correlations from the multivariate analysis).

\section{DISCUSSION}

Heritability estimates of BCS when using RR were consistent across lactation (Figure 3), ranging from 0.32 (d 0) to 0.24 (d 200). A feature of the analysis in the present study was fitting a continuous function to model residual variation, which appeared to overcome some of the problems noted in other studies. One of the reasons given by Berry et al. (2003) for large genetic variation at the peripheries of time periods was that heterogeneous

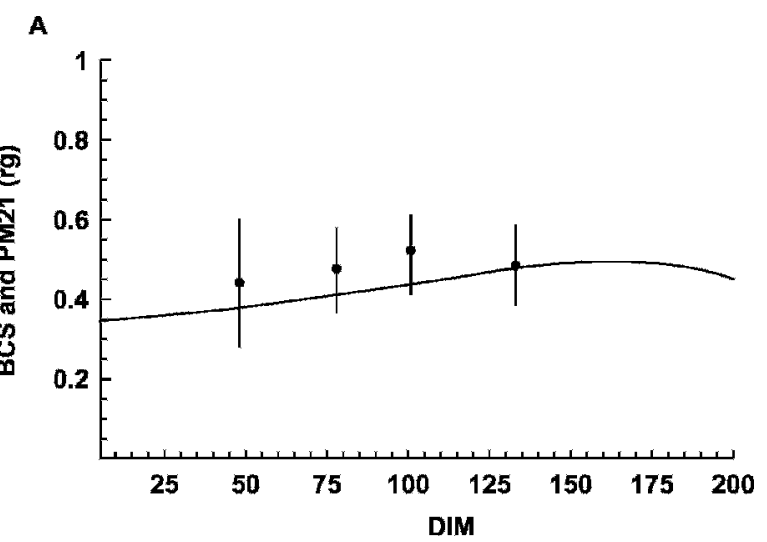

B

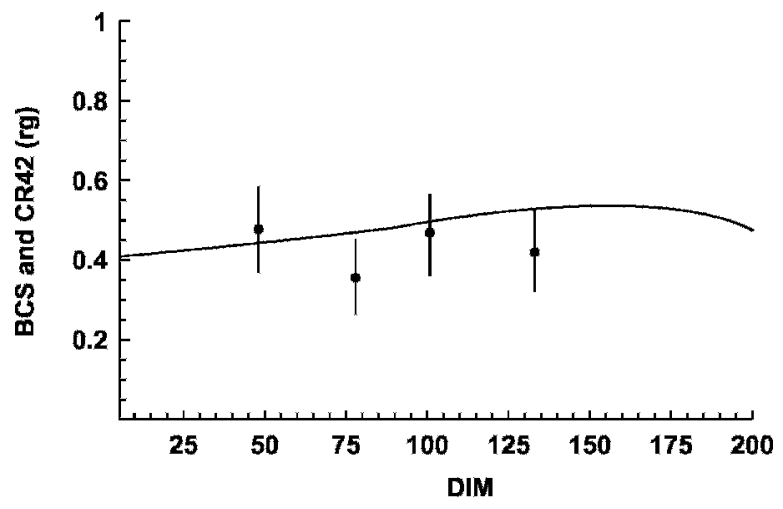

C

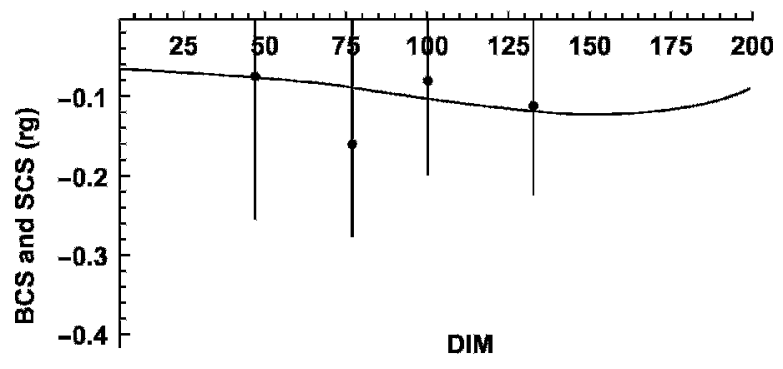

D

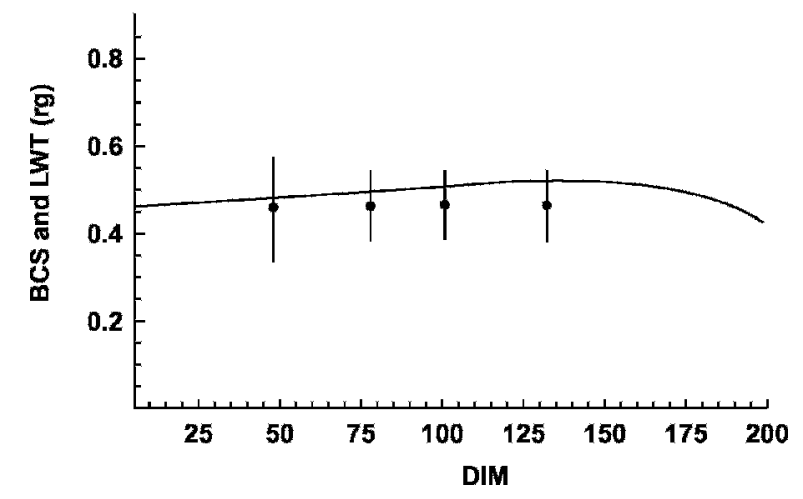

Figure 6. Genetic correlations (rg) between BCS and (A) presented for mating within the first $21 \mathrm{~d}$ from the herd's planned start of mating (PM21), (B) calving in the first $42 \mathrm{~d}$ from the herd's planned start of calving (CR42), (C) log-transformed SCC (SCS), and (D) live weight (LWT). The bars indicate the 95\% confidence interval. 
residual variation was only considered in blocks. In the present study, residual variation was modeled as a continuous function and both genetic and residual variation were elevated in early lactation (Figure 2), resulting in more consistent heritability estimates from calving to approximately d 150 of lactation. Elevated genetic and residual variances at the start of lactation might be expected, because both genetic and environmental differences between animals are most extremely expressed, whereas body tissue reserves that accumulated during pregnancy are mobilized at their greatest rate in early lactation to support energetic demands (Friggens et al., 2004). The paucity of data in the first week of lactation and the mathematical behavior of polynomials at data extremities could also have contributed to the trajectories of residual and genetic variance curves observed in previous studies.

Variance components from a multivariate analysis of BCS divided into data blocks were used to determine starting values for the $R R$ analysis. Heritabilities calculated from this analysis were consistently smaller than those from the RR analysis, which could partly have been due to different models being fitted, as it was not appropriate to fit a permanent environmental effect in the multivariate analyses because few animals had repeated records within the same block of data. Approximately $50 \%$ of cows had 2 BCS records. Also, in the multivariate analysis, residual variation was assumed to be the same within each block of analysis. It would be desirable to fit an RR model to both BCS and other periodically recorded traits, such as milk yield, to estimate genetic covariances between 2 longitudinal traits. However, this type of analysis was technically infeasible with this data set given the computer resources available.

The BCS of $J$ and NAHF were approximately 0.3 BCS points lower than the BCS of NZHF (Table 1). Differences between the same Holstein-Friesian strains observed in experimental herds in New Zealand and Ireland are consistent with these results (Horan et al., 2005; Macdonald et al., 2005). In those studies, NAHF had lower BCS than NZHF strains throughout lactation.

Milk production environments typical to New Zealand are seasonal and reliant on pasture production. There is often a period in the late summer and early autumn when pasture growth slows (in response to reduced rainfall). When this happens, cattle may need to mobilize body reserves to obtain sufficient energy to continue lactation. If BCS of individual cows are already assessed as being too low, then management decisions to dry off need to be made. Macdonald et al. (2005) noted that when BCS was a major decision rule in drying off dairy cows, a strain of NAHF had shorter lacta- tion lengths than NZHF cows when managed in similar systems. It is likely that conditions in NZ have favored cows that have body reserves in midlactation that can be mobilized later in lactation. The genetic correlation estimates between production traits and BCS support this observation, with the genetic correlation between BCS and 270-d yield of fat (Figure 5) in particular changing from moderately positive in early lactation (0.12 at $\mathrm{d} 1$ ) to negative in late lactation (from around $\mathrm{d} 150$ ) and falling to -0.25 by d 200 . The same trend is seen in protein yield and, to a lesser extent, in milk volume. Cows that have high BCS in early lactation (spring) are more likely to have higher total yields of fat and protein because they have more reserves available for production in the autumn, when pasture availability is often limited. Most high-yielding cows would be expected to have low BCS in the autumn; therefore, a negative genetic correlation between production traits and BCS is expected in late lactation.

This result contradicts research from other (nonseasonal) systems found in Europe and North America, where genetic correlations between production and BCS are reported to be negative (e.g., Dechow et al., 2001; Berry et al., 2003). Differences in BCS do appear to be due to differences in body lipid content, because a study of carcass composition by Keane (2003) reported that all measures of fatness were higher in NZHF strains compared with NAHF. In production systems found typically in Europe and North America, fresh pasture plays a relatively minor role in dairy cow diets, which are often based entirely on stored feeds. Thus, selection for production in these types of systems has led to an increase in body tissue mobilization to fuel milk production in early lactation (and hence the negative genetic correlation), and extra feed can be included to strategically sustain milk production. This contrasts with pastoral systems, such as those typical in New Zealand, where there is an advantage in having cows that can retain body tissue in early lactation and mobilize it in later lactation. As observed, the genetic correlation switches from being positive in early lactation to negative in late lactation. This mechanism would appear advantageous to dairy cows in times of negative energy balance, such as dry summer months. The result observed is an environment-specific genetic correlation; in systems such as those typical in NZ, conserving BCS in early lactation is an important strategy to ensure that body reserves are available to mobilize in later lactation.

Achieving 365-d calving intervals is an important management target for New Zealand dairy farms (Holmes et al., 2001). It is interesting to note that although our results on the relationship between production and BCS contradict those from overseas, the ge- 
netic relationship between BCS and fertility is comparable (e.g., Pryce et al., 2000; Dechow et al., 2001; Pryce et al., 2001; Veerkamp et al., 2001; Berry et al., 2002; Dechow et al., 2004; Kadarmideen, 2004; Pryce and Harris, 2004). Because both BCS and milk volume are correlated with fertility (Harris et al., 2005), they have been used as independent predictors of fertility in genetic evaluations of fertility in New Zealand. Because BCS and milk volume have higher heritability estimates than most fertility measures, incorporating them into genetic evaluations of fertility has increased the average reliability of fertility EBV of sires with their first proof (approximately 80 daughters) from 34 to $42 \%$. (Harris et al., 2005).

The results of Berry et al. (2003) showed a tendency for genetic correlations of BCS with fertility to be stronger in mid- to late lactation than in early lactation, albeit with large standard errors, and the authors suggested that using evaluations of BCS in midlactation is preferable, because this is when the heritability of BCS and correlation with fertility are highest. There was also a tendency for genetic correlations between BCS and fertility to be highest in mid- to late lactation in the present study (Figure 6). However, given the size of the standard errors, one can probably safely assume that the correlation between BCS and fertility is reasonably constant across lactation. Furthermore, the genetic correlation of BCS with fertility is highest at the point of greatest data density. Thus, our results support the current method of genetic evaluation of fertility in New Zealand (Harris et al., 2005), in that a simple multitrait model that includes BCS is adequate for providing genetic evaluations for fertility, and extension of the model to include the longitudinal genetic relationship between BCS and fertility is unnecessary.

\section{CONCLUSIONS}

The heritability of BCS is reasonably consistent across lactation. Genetic correlations of BCS with fertility were also consistent across lactation, indicating little advantage in using breeding values for BCS calculated for a particular day from calving in predicting fertility. In pastoral production systems, such as those typical in New Zealand, cows of relatively high BCS in early lactation seems to have been favored, because they have higher total yields of milk solids and good fertility. In addition, this type of cow has body reserves available to convert into extra yield of milk solids in late lactation.

\section{ACKNOWLEDGMENTS}

This project was funded by Dairy InSight (Wellington, New Zealand. We are grateful to the breed societies in New Zealand and Ambreed and Livestock Improvement PT schemes for providing data on BCS.

\section{REFERENCES}

Berry, D. P., F. Buckley, P. Dillon, R. D. Evans, M. Rath, and R. F. Veerkamp. 2003. Genetic parameters for body condition score, body weight, milk yield and fertility estimated using random regression models. J. Dairy Sci. 86:3704-3717.

Berry, D. P., F. Buckley, P. Dillon, R. D. Evans, M. Rath, and R. F. Veerkamp. 2002. Genetic parameters for level and change of body condition score and body weight in dairy cows. J. Dairy Sci. 85:2030-2039.

Dechow, C. D., G. W. Rogers, and J. S. Clay. 2001. Heritability and correlations among body condition score loss, body condition score, production traits and reproductive performance. J. Dairy Sci. 85:3062-3070

Dechow, C. D., G. W. Rogers, L. Klei, T. J. Lawlor, and P. Van Raden. 2004. Body condition scores and dairy form evaluations as indicators of days open in US Holsteins. J. Dairy Sci. 87:3534-3541.

Edmondson, A. J., I. L. Lean, L. D. Weaver, T. Farver, and G. Webster. 1989. A body condition scoring chart for Holstein dairy cows. J. Dairy Sci. 72:68-78.

Friggens, N. C., K. L. Ingvartsen, and G. C. Emmans. 2004. Prediction of body lipid change in pregnancy and lactation. J. Dairy Sci. 87:988-1000.

Garnsworthy, P. C. 1988. The effect of energy reserves at calving on performance of dairy cows. Pages 157-170 in Nutrition and Lactation in the Dairy Cow. P. C. Garnsworthy, ed. Butterworths, London, UK.

Gilmour, A. R., B. J. Gogel, B. R. Cullis, S. J. Welham, and R. Thompson. 2002. ASReml User Guide, Release 1.0. VSN International Ltd., Hemel Hempstead, UK.

Harris, B. L., and E. S. Kolver. 2001. Review of Holsteinization on intensive pastoral dairy farming in New Zealand. J. Dairy Sci. 84(E. Suppl.):E56-E61.

Harris, B. L., and A. M. Winkelman. 2004. Test-day model for genetic evaluation of somatic cell count in New Zealand. Interbull Bull. 32:101-104.

Harris, B. L., J. E. Pryce, Z. Z. Xu, and W. A. Montgomerie. 2005. Fertility breeding values in New Zealand, the next generation. Interbull Bull. 33:47-50.

Holmes, C. W., I. M. Brookes, D. J. Garrick, D. D. S. Mackenzie, T. J. Parker, and G. F. Wilson. 2001. Milk Production from Pasture. Massey University Press, Palmerston North, New Zealand.

Horan, B., J. F. Mee, P. O'Connor, M. Rath, and P. Dillon. 2005. The effect of strain of Holstein-Friesian cow and feeding system on reproductive performance in a spring-calving milk production system. Anim. Sci. 79:453-468.

Jaffrezic, F., I. M. S. White, R. Thompson, and W. G. Hill. 2000. A link function approach to model heterogeneity of variance over time in lactation curve analysis. J. Dairy Sci. 84:1255-1264.

Johnson, D. L. 1996. Estimation of lactation yield from repeated measures of test day yields. Proc. N. Z. Soc. Anim. Prod. 56:16-18.

Johnson, D. L., and R. Thompson. 1995. Restricted maximum likelihood estimation of variance components for univariate animal models using sparse matrix techniques and average information. J. Dairy Sci. 84:1255-1264.

Jones, H. E., I. M. S. White, and S. Brotherstone. 1999. Genetic evaluation of Holstein-Friesian sires for daughter condition-score changes using random regression model. Anim. Sci. 68:467-475.

Kadarmideen, H. N. 2004. Genetic correlations among body condition score, somatic cell score, milk production and conformation traits in dairy cows. Anim. Sci. 79:191-201.

Keane, M. G. 2003. Beef production from Holstein-Friesian bulls and steers of New Zealand and American descent and Belgian Blue $\times$ Holstein-Friesians, slaughtered at two weights. Livest. Prod. Sci. 84:207-218. 
Kirkpatrick, M., D. Lofsvold, and M. Bulmer. 1990. Analysis of inheritance, selection and evolution growth trajectories. Genetics 124:979-993.

Koch, R. M., G. E. Dickerson, L. V. Cundiff, and K. E. Gregory. 1985. Heterosis retained in advanced generations of crosses among Angus and Hereford cattle. J. Anim. Sci. 60:1117-1132.

Koenen, E. P. C., and R. F. Veerkamp. 1998. Genetic covariance functions for liveweight, condition score, and dry matter intake measured at different lactation stages of Holstein-Friesian heifers. Livest. Prod. Sci. 57:67-77.

Macdonald, K., B. Thorrold, C. Glassey, C. W. Holmes, and J. E. Pryce. 2005. Impact of farm management decision rules on the production and profit of differing strains of Holstein-Friesian dairy cows. Proc. N. Z. Soc. Anim. Prod. 65:40-45.

Pryce, J. E., M. P. Coffey, and S. Brotherstone. 2000. The genetic relationship between calving interval, condition score and linear type and management traits in pedigree registered Holstein dairy cows. J. Dairy Sci. 83:2664-2671.
Pryce, J. E., M. P. Coffey, and G. Simm. 2001. The relationship between body condition score and reproductive performance. J. Dairy Sci. 84:1508-1515.

Pryce, J. E., and B. L. Harris. 2004. Genetic and economic evaluation of dairy cow body condition score in New Zealand. Interbull Bull. 32:82-85.

Pryce, J. E., B. L. Harris, and W. A. Montgomerie. 2005. Breeding for body condition score in dairy cows. Pages 72-75 in Proc.16th Conf. Assoc. Advancement of Animal Breeding and Genetics, Noosa Lakes, Australia. CSIRO, Collingwood, Victoria, Australia.

Pryce, J. E., B. L. Harris, D. L. Johnson, and W. A. Montgomerie. 2006. Body condition score as a candidate trait in the Breeding Worth Dairy Index. Proc. N. Z. Soc. Anim. Prod. 66:103-106.

Veerkamp, R. F., E. P. C. Koenen, and G. de Jong. 2001. Genetic correlations among body condition score, yield, and fertility in first parity cows estimated by random regression models. J. Dairy Sci. 84:2327-2335

Veerkamp, R. F., and R. Thompson. 1999. A covariance function for feed intake, live weight, and milk yield estimated using a random regression model. J. Dairy Sci. 82:1565-1573. 